\title{
Patrimônio industrial e os órgãos de preservação na cidade de São Paulo *
} Angela Rosch Rodrigues**

\section{Resumo}

Este trabalho tem como objetivo analisar o processo de reconhecimento do patrimônio industrial na cidade de São Paulo pelos órgãos públicos de preservação nas esferas nacional (IPHAN), estadual (CONDEPHAAT) e municipal (CONPRESP) através do estudo das instruções de tombamento e das trajetórias dos referidos órgãos, recuperando os critérios que influenciaram as determinações que têm contemplado os remanescentes industriais. O significativo aumento no número de tombamentos verificado nas últimas duas décadas, por um lado reflete a conscientização sobre seu significado no âmbito acadêmico e social, e por outro expõe as forças do mercado imobiliário e os impasses com os proprietários.

Palavras Chaves: Preservação arquitetônica industrial. Patrimônio industrial. Arquitetura paulista.

Industrial heritage and the agencies of preservation in the city of São Paulo

\begin{abstract}
This study aims to analyze the process of recognition of industrial heritage in the city of São Paulo by the public agencies of preservation in the national (IPHAN), state (CONDEPHAAT) and municipal (CONPRESP) spheres, through the study of the official determinations of protection and through the trajectories of those agencies, recovering the criteria that influenced the decisions that have contemplated the industrial remaining. The significant increase in the number of the official protections verified over the last two decades on the one hand reflects the awareness of its significance in the academic and social ambit; on the other, exposes the forces of real estate and the impasses with the owners.
\end{abstract}

Key words: Preservation of industrial architecture. Industrial heritage. Paulista architecture. 


\section{Introdução}

No cenário internacional, a constatação de que as transformações provocadas no pós Segunda Guerra ameaçavam remanescentes significativos de nossa cultura recente, proporcionou as motivações para estudá-los e preservá-los. Nesse contexto, os movimentos para a valorização do patrimônio industrial começaram a emergir com maior profusão, principalmente na Inglaterra a partir da década de 1950, através do campo de estudo denominado "arqueologia industrial" (1). A ampliação do conceito de bem cultural expressa no primeiro artigo da Carta de Veneza (1964) (2) reflete também uma possibilidade de abertura que engloba, dentre outros, a valorização de remanescentes ligados à história da industrialização.

No âmbito nacional o patrimônio industrial (3) passou a ganhar mais atenção a partir de meados de 1960, quando se verificam algumas das iniciativas e estudos pioneiros de preservação voltados à compreensão do valor desses artefatos. 0 trabalho Fábrica São Luiz de Itu: um estudo de arqueologia industrial de Warren Dean publicado em 1976 pode ser considerado a primeira pesquisa acadêmica sobre uma indústria brasileira, sob a ótica da arqueologia industrial. Este mesmo autor já havia estudado o processo econômico de industrialização no Estado, cujo trabalho A industrialização de São Paulo, 1880 - 1945 publicado em 1971, sobre a relação entre a atividade industrial e a produção cafeeira, é uma importante referência.

Também contribuíram para uma melhor compreensão do patrimônio industrial, os estudos sobre a história da técnica brasileira e sua interface com a manufatura agrícola do período colonial, constituindo-se uma linha de pesquisa importante para o desenvolvimento da disciplina "arqueologia industrial" no Brasil. Em 1976, foi lançado o Guia para a história da técnica no Brasil Colônia de Júlio Katinsky, que apresentava a preocupação de um grupo de estudos da Universidade de São Paulo que pesquisava remanescentes de diversas atividades manufatureiras (fazendas de café, engenhos de açúcar e espaços fabris urbanos). Ruy Gama, em 1978, concluiu o trabalho Engenho e tecnologia, (publicado em 1983) e em 1986 publicou $A$ tecnologia e o trabalho na história. 
A cidade de São Paulo, que tem talvez o maior legado industrial do país com marcante presença para seu desenvolvimento urbano, teve os primeiros estudos para tombamento desses remanescentes a partir de meados da década de 1970. A análise do processo de reconhecimento do patrimônio industrial pelos órgãos públicos de preservação nessa cidade - IPHAN, CONDEPHAAT e CONPRESP pode ajudar a compreender a atual situação desse patrimônio na capital paulista.

Assim, com base nas listagens oficiais dos referidos órgãos e nas referências bibliográficas complementares que abordam o histórico dos mesmos, buscamos recuperar a trajetória das políticas públicas de preservação. Para o melhor acompanhamento do processo, analisamos isoladamente cada uma das instituições, cuja recuperação cronológica das ações preservacionistas em prol do patrimônio industrial visa esclarecer a compreensão e o significado desses remanescentes nos distintos órgãos patrimoniais.

\section{Federal}

As iniciativas brasileiras em relação à preservação patrimonial desenvolveram-se principalmente a partir da década de 1920 consolidando-se com a criação do Serviço do Patrimônio Histórico e Artístico Nacional (SPHAN) (4) em 1937. Para a compreensão da formulação do decreto lei de 1937 que instituiu o SPHAN é necessário situar que, no âmbito político, a constituição do Estado Novo por Getúlio Vargas e a nomeação do mineiro Gustavo Capanema para o Ministério de Educação e Saúde foi determinante. O governo do Estado Novo abordava necessariamente a valorização do nacional através da educação, pretendendo constituir a Nação pelas suas referências simbólicas (FONSECA, 1997, p. 111) atribuindo à questão da preservação patrimonial grande interesse, o que levou à solicitação por parte de Capanema a Mário de Andrade de um anteprojeto para a criação de uma instância federal que abrigasse os trabalhos sobre o patrimônio histórico. Esse anteprojeto de Mário de Andrade se concentrou em aspectos conceituais antropológicos sendo bastante amplo em sua acepção de "bem cultural", além de instituir as quatro determinações para as inscrições nos Livros de Tombo: 1. Belas artes; 2. Histórico; 3. Arqueológico, etnográfico e paisagístico; 4. Artes aplicadas. 
Para o que concerne a este estudo, pode ser destacado que, nesse anteprojeto, Mário de Andrade havia imaginado museus que expusessem a produção e beneficiamento do café expondo as mais diversas etapas do plantio, sistemas de lavagem e secagem, os maquinários desmontados da torrefação e da manufatura mecânica até chegar ao produto final abordando as esferas científicas, técnicas e industriais; ele aventou também a possibilidade de estender esse tipo de experiência a outros produtos agrícolas como algodão, açúcar e laranja; ou processos de extração como o ferro, ouro, carnaúba, borracha; e meios de transporte como avião, locomotiva; dentre outros (ANDRADE apud LEMOS, 2006, p. 41-42).

Os critérios e juízo de valores efetivamente adotados pelo SPHAN não continham a mesma amplitude cultural vislumbrada por Mário de Andrade e passaram a se pautar, principalmente, na distinção do passado a ser preservado e o valor cognitivo que poderia dele aflorar de modo a contribuir para a construção de um senso de nação brasileira naquilo que a distinguia. Nesse sentido, se constituíram os critérios de excepcionalidade e representatividade em que a arte colonial (as raízes portuguesas da região do Minho) e barroca se tornaram determinantes com ênfase à arquitetura religiosa e aos edifícios interpretados como monumentos isolados, relacionando - os a feitos históricos de determinados grupos sociais (RODRIGUES, 2001, p. 50).

Durante esse período, o patrimônio no Estado de São Paulo também era atribuição exclusiva do SPHAN, resultando no reconhecimento de determinados tipos de edificações relacionadas ao povoamento do litoral, às casas rurais bandeiristas, sedes de antigas fazendas de café e igrejas de seiscentos (RODRIGUES, 2000, p. 36-37). No caso específico da capital paulista, nesse primeiro momento o SPHAN não vislumbrava o ciclo que simbolizava a primeira República e a intensa experiência urbano-industrial que possibilitou inclusive o desenvolvimento da arte moderna (RUBINO, 1991 apud FENERICH, 2000, p. 85).

Tendo como referência essa situação da política de preservação brasileira entre as décadas de 1930 a 1960 é possível constatar que poucos remanescentes relacionados ao conceito de patrimônio industrial no âmbito nacional foram 
efetivamente tombados nesse período (Tabela 01). Em 1938 houve um primeiro registro no livro histórico de remanescentes de uma fábrica em Ouro Preto (MG) Fábrica de Ferro Patriótica - que deve ser interpretado a partir dos critérios e valores característicos dessa fase, ou seja, a compreensão de um monumento relacionado a feitos históricos referentes ao processo de colonização. Tendo em vista a correlação entre patrimônio industrial e a produção manufatureira colonial, podem ser destacados alguns exemplares como engenhos tanto na região nordeste como no Estado de São Paulo onde são referências a Fazenda do Engenho d’Água (Ilhabela, SP) tombada em 1951 e o Engenho São Jorge dos Erasmos em Santos tombado em 1963. É curioso verificar ainda o tombamento em 1954 do denominado primeiro trecho ferroviário do país Mauá - Fragoso, 14 km, (Magé - RJ). A maior incidência desses tombamentos é no Livro Histórico, embora hajam alguns cadastrados também no Livro de Belas Artes ou ainda no Livro Arqueológico, Etnográfico e Paisagístico.

No Estado de São Paulo ocorreu em 1964 a primeira iniciativa nacional de efetiva preservação de um conjunto industrial: a Real Fábrica de Ferro São João do Ipanema (Iperó), implantada a partir de 1810. Conforme destaca Cunha, a inscrição somente se deu no Livro Histórico, acompanhando a "amargurada recomendação de Mário de Andrade" por tratar-se de: "Remanescentes de arqueologia industrial do primeiro complexo funcionante para a exploração e fabricação de ferro no Brasil, [...]" (CUNHA, 2005, p. 114). Ruy Gama destacou no $1^{\circ}$ Seminário Nacional de História e Energia em 1986 o pioneirismo da intervenção na Fábrica de Ferro de Ipanema pelo SPHAN antes da difusão do conceito "arqueologia industrial" no Brasil, ainda que constatando a limitação desse trabalho na completa acepção que o tema envolve:

[...] existe lá um conjunto de edifícios, dois dos quais foram restaurados e preservados pelo Serviço do Patrimônio Histórico e Artístico Nacional [...]. Pois bem, isto se encaixaria perfeitamente no objeto e na preocupação de uma arquitetura industrial. E foi feita no Brasil antes que se falasse sequer em arqueologia industrial. Corremos o risco, portanto, de adotar um nome novo e importado para denominar uma coisa que, de alguma forma, já vinha sendo feita no Brasil. É claro que este trabalho de restauração e de preservação da Fábrica de Ferro de Ipanema se restringiu aos edifícios. Boa parte daquelas máquinas e dos equipamentos ali usados ficou perdida para sempre, alguns restos de forma que deveriam ter sido restaurados, 
algumas máquinas, alguns moinhos para trituração de minério, os restos do antigo caminho de ferro por onde o ferro era trazido das jazidas próximas para o recinto da fábrica, etc. [...] Porém é indiscutivelmente um marco. É um marco que antecede o nome arqueologia industrial. (GAMA, 1986, p. 256)

\begin{tabular}{ccccc}
\hline & $\begin{array}{c}\text { Data } \\
\text { Tombamento }\end{array}$ & Tipo de Processo & Nome & Local \\
\hline 1 & $30 / 06 / 38$ & T - L. H. & Fábrica de Ferro Patriótica, ruínas & Ouro Preto, MG \\
\hline 2 & $06 / 09 / 43$ & T - L.H. & Engenho Matoim & Candeias, BA \\
\hline 3 & $16 / 09 / 43$ & T - L. H. e L.B.A & Sonhar do Unhão e Capela Nossa Senhora da Conceição & Salvador, BA \\
\hline 4 & $14 / 09 / 44$ & T - L. H. e L.B.A & Engenho Freguesia & Candeias, BA \\
\hline 5 & $22 / 10 / 51$ & T - L.B.A & Fazenda do Engenho d Água & Ilhabela, SP \\
\hline 6 & $07 / 05 / 54$ & T - L. H. & Trecho ferroviário Mauá-Fragoso & Magé, RJ \\
\hline 7 & $02 / 07 / 63$ & T - L.H. & Engenho dos Erasmos & Santos, SP \\
\hline 8 & $24 / 09 / 64$ & T - L.H. & Real Fábrica de Ferro São João do Ipanema & Iperó, SP \\
\hline
\end{tabular}

TABELA 01: Patrimônio industrial tombado no Brasil pela esfera federal de 1936 a 1967; (T: Tombado; L.H.: Livro Histórico; L.B.A: Livro Belas Artes). Fonte: Elaborada pelo autor a partir de dados do Arquivo Noronha Santos, acesso em 10 nov. 2011, disponível em: <http://www.iphan.gov.br/ans/inicial.htm> e do "Bens Móveis e Imóveis Inscritos nos Livros do Tombo do Instituto do Patrimônio Histórico e Artístico Nacional (1938-2009), Quinta Edição 2009", acesso em 17 abr. 2012, disponível em: <http://portal.iphan.gov.br/portal/montarPaginaSecao.do?id=13928\&retorno=paginal phan >.

A partir de meados da década de 60, evidenciam-se alterações na política de salvaguarda federal reforçadas ainda pela necessidade da descentralização nacional. Na década de 1970, as discussões sobre a preservação patrimonial deslocam-se do objeto, ou seja, do monumento isolado para a interação com o conjunto integrando o patrimônio ao planejamento urbano e territorial. Ampliou-se também o recorte cronológico, com pesquisas referentes ao Império e República possibilitando a incorporação de novos elementos à memória histórica. Tornou-se necessário então, atualizar a administração dos bens tombados e a composição do patrimônio.

Com o objetivo de atender a essa demanda criou-se o Centro Nacional de Referência Cultural (CNRC) em 1975 cujo mentor foi Aloísio Magalhães através de um convênio firmado entre o Governo do Distrito Federal (pela Secretaria da Educação e Cultura) e o Ministério de Indústria e Comércio (pela Secretaria de Tecnologia Industrial) (FONSECA, 1997, p. 163). É interessante observar que alguns objetivos do CNRC tangenciaram em alguns aspectos a questão estudada aqui, da abordagem ao patrimônio industrial, na medida em que enfocava preferencialmente: 
"o trato da matéria prima, as formas de tecnologia pré-industrial, as formas do fazer popular, a invenção de objetos utilitários" (MAGALHÃES, 1985 apud FONSECA, 1997 , p. 172) contribuindo para ampliar a noção de cultura popular abrangendo as manifestações populares tradicionais e suas interfaces com o mundo industrial urbano (5).

Em 1979 ocorreu a fusão entre o CNRC e o IPHAN, o que contribuiu para uma ampliação conceitual do bem cultural. Na prática, as propostas de tombamento de "novos programas" ou do denominado "patrimônio cultural não consagrado" reforçou a necessidade de organizar novas referências conceituais. Com isso, a ampliação da perspectiva histórica possibilitou a atribuição de valor estético a bens como obras da tecnologia industrial tais como pontes, mercados, fábricas, caixas d’água, faróis, estações ferroviárias, etc. (Tabela 02). Sendo assim, ao longo da década de 1980, começaram a chegar ao conselho pedidos de tombamento dos "novos programas" como marcos da história da ciência e da tecnologia como a Estação Ferroviária de Lassance (MG), ou exemplares da arquitetura do ferro (pontes, mercados, caixas d’água, açude, etc.), ou ainda exemplares da arquitetura civil (curtumes, fábricas e conjuntos habitacionais populares); e até "fazeres", como o objeto da proposta de tombamento da Fábrica de Vinho de Caju Tito Silva, Paraíba (FONSECA, 1997, p. 239-240).

É também nesse período que ocorre em São Paulo o já mencionado $1^{\circ}$ Seminário Nacional de História e Energia (1986), que foi o primeiro congresso brasileiro em que se discutem aspectos do patrimônio industrial. O evento realizado pelo Departamento de Patrimônio Histórico da Eletropaulo, contou com convidados internacionais (o português José Lopes Cordeiro e o belga Eddy Stols); dentre os brasileiros destacam-se as discussões apresentadas por Ruy Gama, Ulpiano Bezerra de Menezes e Margarida Davina Andreatta.

Nesse seminário, Meneses, Gama e Andreatta reforçaram aspectos da noção de patrimônio industrial e a forma com que é apropriada para o caso brasileiro. Um dos aspectos discutidos é o equívoco de considerar o patrimônio industrial exclusivamente a partir da história da ciência e da técnica o que pode ser muito restritivo. Outro aspecto é o recorte cronológico da documentação industrial, nesse 
sentido Gama destaca: "um vício de nascença da arqueologia inglesa que é a valorização excessiva da Revolução Industrial" (GAMA, 1986, p. 259). São apresentados exemplos de patrimônio industrial no caso brasileiro e sua relação com a dinâmica sócio-econômica, particularmente sobre a ocupação portuguesa e cultivo agrícola, refletindo as linhas de pesquisa que estavam sendo desenvolvidas por Gama e Andreatta. Gama defende que o estudo da arqueologia industrial no país deveria englobar as primeiras instalações de caráter manufatureiro - os engenhos. Para ele os engenhos bem como a atividade mineira e os estaleiros de construção naval estão adiante do processo de produção do sistema produtivo do qual decorrem as mudanças nas relações de produção (GAMA, 1986, p. 257).

Andreatta discorre sobre o trabalho de resgate arqueológico do Engenho dos Erasmos, por ela coordenado, em Santos (SP) entre 1997 e 1999. Em dezembro de 1999, ocorre o $2^{\circ}$ Seminário Nacional de História e Energia, em São Paulo, realizado pela Fundação Patrimônio Histórico da Energia de São Paulo, em que foram debatidas questões acerca do patrimônio industrial sob a coordenação de Regina Maria Prosperi Meyer e Raquel Rolnik.

Analisando os bens tombados pelo IPHAN no Estado de São Paulo, verificam-se poucos referentes às grandes transformações urbanas ocorridas a partir do fim do século 19. Mais recentemente, alguns exemplares relacionados às ferrovias foram acrescidos, como a Estação Ferroviária de Mayrink, o conjunto da Companhia da Estrada de Ferro de Jundiaí e a Vila de Paranapiacaba (Santo André). Na cidade de São Paulo o primeiro e único tombamento federal de patrimônio industrial foi a Estação Ferroviária da Luz (1895-1901) que ocorreu somente em 1996, vinte anos após o pedido inicial ter sido solicitado. Em 1976 foi aberto o processo de tombamento nos órgãos Federal e Estadual. Durante o processo de estudo no IPHAN houve controvérsias por parte dos relatores quanto à importância da expressividade dos valores artístico, histórico e paisagístico do conjunto que justificasse um reconhecimento no âmbito nacional, dessa forma o IPHAN se limitou à recomendação da preservação estadual. A Estação da Luz foi então tombada pelo CONDEPHAAT em 1982 momento em que o imóvel encontrava-se em situação de emergência mediante às obras que poderiam levar a descaracterizações. Somente em 1996, a Estação da Luz foi tombada pelo IPHAN (FENERICH, 2000, p. 95-97). 


\begin{tabular}{|c|c|c|c|c|}
\hline & $\begin{array}{c}\text { Data } \\
\text { Tombamento }\end{array}$ & Tipo de Processo & Nome & Local \\
\hline 1 & $17 / 12 / 73$ & T - L.H. e L.B.A. & Mercado de São José & Recife, PE \\
\hline 2 & 29/01/81 & $\begin{array}{l}\text { T. - L.H.e } \\
\text { L A.E.P. }\end{array}$ & Sítio do Físico & São Luís, MA \\
\hline 3 & $19 / 05 / 83$ & T - L.B.A. & Cais do Porto: pórtico central e armazéns & Porto Alegre, RS \\
\hline 4 & $19 / 07 / 84$ & $\begin{array}{l}\text { T- L.B.A. e } \\
\text { L.A.E.P. }\end{array}$ & Açude do Cedro & Quixadá, CE \\
\hline 5 & $19 / 07 / 84$ & T - L.B.A. & Caixa d’Água & Pelotas, RS \\
\hline 6 & $06 / 09 / 84$ & T - L.H. & Fábrica de Vinho Tito Silva & João Pessoa, PB \\
\hline 7 & $01 / 07 / 85$ & T. - L.H. & Antiga Estação Ferroviária de Lassance & Lassance, MG \\
\hline 8 & $24 / 04 / 85$ & T - L.H. e L.B.A. & Engenho do Mate & Campo Largo, PR \\
\hline 9 & $24 / 04 / 85$ & T - L.H. e L.B.A. & Reservatório de Mocó & Manaus, AM \\
\hline 10 & $\begin{array}{c}\text { 30/09/1985 (L.B.A.) } \\
\text { 14/08/1986 } \\
\text { (L. A.E.P.) }\end{array}$ & $\begin{array}{l}\text { T - L.B.A. e } \\
\text { L.A.E.P. }\end{array}$ & Casarão do Chá & Moji das Cruzes, SP \\
\hline 11 & $01 / 07 / 87$ & T - L.H. & Fábrica Santa Amélia & São Luís, MA \\
\hline 12 & $01 / 07 / 87$ & T - L.H. e L.B.A. & Mercado Municipal & Manaus, AM \\
\hline 13 & $14 / 10 / 87$ & $\begin{array}{l}\text { T- L.B.A.e } \\
\text { L.A.E.P. }\end{array}$ & $\begin{array}{l}\text { Porto de Manaus } \\
\text { (Conj. Arquitetônico) }\end{array}$ & Manaus, AM \\
\hline 14 & $13 / 06 / 88$ & T - L.H. & Ponte do Imperador & Ivoti, RS \\
\hline 15 & $03 / 08 / 89$ & T - L.H. e L.B.A & Complexo Ferroviário de São João del Rei & São João del Rei e Tiradentes, MG \\
\hline 16 & $10 / 10 / 96$ & T - L.H. e L.B.A & Estação da Luz & São Paulo, SP \\
\hline 17 & $05 / 08 / 98$ & T - L.H. & Ponte Hercílio Luz & Florianópolis, SC \\
\hline 18 & 06/09/98 & T- L.H. & $\begin{array}{c}\text { Engenho Central São Pedro } \\
\text { (Cia Progresso Agrícola do Maranhão) }\end{array}$ & Pindaré - Mirim, MA \\
\hline 19 & $03 / 12 / 98$ & T - L.H. & Base aérea Santa Cruz: Hangar Zepelin & Rio de Janeiro, RJ \\
\hline 20 & $08 / 07 / 04$ & T - L.B.A. & Estação Ferroviária Mayrink & Mairinque, SP \\
\hline 21 & $14 / 07 / 04$ & T - L.B.A. & $\begin{array}{l}\text { Conjunto da Companhia de Estrada de } \\
\text { Ferro }\end{array}$ & Jundiaí, SP \\
\hline 22 & 07/01/08 & T - L.H.e L.A.E.P. & $\begin{array}{l}\text { Pátio Ferroviário da Estrada de Ferro } \\
\text { Madeira-Manoré }\end{array}$ & Porto Velho, RO \\
\hline 23 & $30 / 09 / 08$ & T-L.H. & Vila Ferroviária de Paranapiacaba & Santo André, SP \\
\hline
\end{tabular}

TABELA 02: Patrimônio industrial tombado no Brasil pelo IPHAN a partir da década de 1970; (T: Tombado; L.H.: Livro Histórico; L.B.A.: Livro Belas Artes; L.A.E.P.: Livro Arqueológico, Etnográfico e Paisagístico). Fonte: Elaborada pelo autor a partir de dados do Arquivo Noronha Santos, acesso em 10 Nov. 2011, disponível em: <http://www.iphan.gov.br/ans/inicial.htm> e do “Bens Móveis e Imóveis Inscritos nos Livros do Tombo do Instituto do Patrimônio Histórico e Artístico Nacional (1938-2009), Quinta Edição - 2009", acesso em 17 abr. 2012, disponível em: <http:// portal. iphan.gov. br/portal/montarPaginaSecao.do? id=13928\&retorno=paginal phan>.

\section{Estadual - CONDEPHAAT:}

Em 1968 foi criado o órgão específico para o Estado de São Paulo, o Conselho da Defesa do Patrimônio Histórico, Arqueológico, Artístico e Turístico (CONDEPHAAT), no contexto de descentralização da política nacional de preservação. A princípio, este órgão estadual manteve critérios semelhantes à política nacional de preservação que primava, especialmente pelo patrimônio relacionado à colonização, à expansão territorial ou a ciclos econômicos determinantes que no caso de São Paulo relacionava-se com a produção e exportação de café. A industrialização e seus remanescentes passaram a ser definitivamente incorporados a partir da 
década de 1980. Será analisado a seguir o desenvolvimento da prática de preservação exercida pelo CONDEPHAAT no que tange ao patrimônio industrial na cidade de São Paulo uma vez que esse patrimônio está intimamente ligado ao desenvolvimento urbano compondo um importante referencial à memória, o que não poderia ser ignorado.

De acordo com a pesquisadora Marly Rodrigues, numa primeira fase (1969-1975), o CONDEPHAAT manteve critérios similares aos da política de preservação da esfera federal observando valores essencialmente relacionados à sua materialidade intrínseca e à sua representatividade para a história regional e da arquitetura, enfatizando a monumentalidade de remanescentes relacionados a feitos históricos importantes referentes, principalmente, aos processos de colonização e expansão territorial. Ainda que a representatividade arquitetônica fosse um critério determinante na atuação do CONDEPHAAT, o conceito de uma segmentação por "ciclos econômicos" aos poucos passou a vigorar como parâmetro de seleção do que deveria ser preservado como meio de situar o bem temporal e historicamente. $\mathrm{O}$ "ciclo industrial" estava incorporado a essa concepção, o que seria um passo importante para a ampliação do conceito de bem cultural abrangendo obras mais recentes e representativas de uma memória que persistia viva na população urbana (RODRIGUES, 2000, p. 64).

Em 1974 a Faculdade de Arquitetura e Urbanismo da USP e o IPHAN promoveram o "Curso de Preservação e Restauro de Monumentos" que introduziu o conceito de "patrimônio cultural" nas discussões dos meios acadêmicos, principalmente em função das aulas ministradas por Hugues Varine Bohan, da UNESCO. Essa ampliação conceitual não se refletiria imediata e diretamente na prática do CONDEPHAAT, mas seria importante para o período posterior.

Numa segunda fase (1975 a 1982) o CONDEPHAAT passou a fazer parte da Secretaria de Cultura, Ciência e Tecnologia. Em função daquilo que havia sido apresentado por Varinne-Bohan e em meio a contradições, o órgão estadual adotaria novos objetos de proteção e o patrimônio também passaria a ser entendido em sua dimensão urbana. Tratava-se de um momento em que a sociedade 
começava a perceber a importância da memória e da preservação como um direito social (RODRIGUES, 2000, p. 80).

No início de 1976, o Conselho do Governo aprovou a Política de Desenvolvimento Urbano e Regional do Estado elaborada pela Secretaria de Economia e Planejamento, em que estava incluso um Programa de Preservação e Revitalização do Patrimônio Ambiental Urbano que preconizava o desenvolvimento sem a destruição de referencias culturais características. Para os planejadores envolvidos no Programa, o patrimônio histórico também integrava o ambiente urbano, dessa forma o conceito de "patrimônio ambiental urbano" desenvolveu-se e possibilitou um reconhecimento de diferentes representações de "qualquer passado". Nesse contexto, outra percepção que se desenvolveu foi a necessidade de compreender os testemunhos do passado através do presente. Conforme pesquisadores como Ulpiano Bezerra de Menezes o caráter dinâmico do patrimônio deveria ser destacado através de análises que o inserissem no contexto das transformações sociais, como produto cultural com uma linguagem simbólica. O CONDEPHAAT deveria então estabelecer critérios para a seleção dos bens; essa necessidade de atuação contribuiu para ampliar o conceito de patrimônio, pois se passou a valorizar também aspectos socioculturais que compõem os remanescentes físicos, possibilitando incorporar edificações mais recentes (RODRIGUES, 2000, p. 84-86 e p. 90-91).

Com a abertura conceitual em andamento iniciam-se no CONDEPHAAT os primeiros estudos sobre o patrimônio industrial da cidade de São Paulo. Nesse contexto foi tombada a Vila Economizadora (construída entre 1908-1925) como conjunto que remete à memória operária e ao desenvolvimento industrial. Dois outros exemplares tiveram o processo de tombamento iniciado nesse período (meados da década de 1970): o já mencionado edifício da Estação da Luz (1867) que era protegido pela lei municipal Z8 - 200 e estava ameaçado por descaracterizações a serem implantadas pela Rede Ferroviária Federal, a estação foi tombada pelo CONDEPHAAT em 1976 e a decisão somente foi homologada em 1982; e a Estação do Brás (1897) que teve seu processo iniciado em 1978 e a efetivação do tombamento se deu em 1982. 
Na década de 1980, no bojo do processo de abertura que se deflagrava no país, houve uma predisposição por parte da sociedade às reflexões sobre a preservação patrimonial no sentido de reivindicar o direito à memória. Nesse quadro verificam-se efetivamente os tombamentos pelo CONDEPHAAT de exemplares relacionados ao passado industrial, não só no Estado (Fábrica de Tecidos São Luiz - Itu, tombado em 1983) como também na cidade de São Paulo. Além da homologação dos tombamentos das estações da Luz e Brás, houve o tombamento em 1985 do Antigo Matadouro da Vila Mariana (1887); em 1986 foi tombado o primeiro conjunto efetivamente relacionado à atividade fabril na cidade, alguns remanescentes do complexo na Água Branca das Indústrias Reunidas Francisco Matarazzo (IRFM) cujas construções eram provenientes a partir da década de 1920.

Esse caso ilustra a conturbada relação entre a questão patrimonial e a valorização imobiliária, um ponto crucial entre a possibilidade de reconhecimento cultural ou a destruição do patrimônio industrial. O corpo técnico considerava todo o complexo potencialmente relevante enquanto bem cultural e estava disposto a levar em consideração a proposta inicial dos proprietários que era a reutilização das edificações para a instalação de um centro comercial (shopping). Embora o imóvel estivesse em estudo e houvesse negociações entre o governo e os proprietários, prevaleceram os interesses desses, pois promoveram a demolição repentina do conjunto da fábrica (6). Do antigo complexo, restaram somente a casa de máquinas e as chaminés, pois os proprietários achavam que somente esses elementos eram importantes. A destruição deste significativo lugar de memória da industrialização de São Paulo foi tolerada sem conseqüências (RODRIGUES, 2000, p. 136 e139).

Na década de 1990 foram adicionados alguns bens à lista do patrimônio industrial do CONDEPHAAT na cidade de São Paulo como a Vila Maria Zélia, tombada em 1992 (embora o processo de tombamento já estivesse aberto desde 1979). A Estação Júlio Prestes, que foi incorporada em 1999, três anos após a inclusão da Estação da Luz pelo IPHAN, num momento de revitalização da área central da cidade. Mais recentemente efetivou-se o tombamento da Estação de Bondes do Brás, em andamento desde 1991 como último remanescente do antigo sistema de transporte coletivo da cidade; bem como as edificações do Complexo do Gasômetro (Casa das Retortas e os Balões da Comgás) e o antigo conjunto Moinhos Minetti Gamba 
(Tabela 03). Está aguardando homologação o tombamento do Moinho Matarazzo e ainda há outros estudos tramitando no órgão como a antiga Fábrica de Seda Ítalo Brasileira na Rua Joli (Brás) e a antiga Fábrica de Tecido Labor (Mooca).

\begin{tabular}{ccccc}
\hline & No Processo & Data Tombamento & Tipo de Processo & Nome \\
\hline 1 & $20097 / 76$ & Res. 25 de 5/5/82 & T & Estação da Luz \\
\hline 2 & $20213 / 77$ & Res. 36 de 27/9/80 & T & V \\
\hline 3 & $20699 / 78$ & Res. 22 de 3/5/82 & T & Estação Do Brás - Santos Jundiaí \\
\hline 4 & $22625 / 83$ & Res. 7 de 4/3/85 & T & Indús trias Reunidas Francisco Matarazzo \\
\hline 5 & $24263 / 85$ & Res. 14 de 5/6/86 & T & Vila Maria Zélia \\
\hline 6 & $24268 / 85$ & Res. 43 de 18/12/92 & T & Estação de Bondes do Brás \\
\hline 7 & $28682 / 91$ & Res. 02 de 23/01/08 & T & Antiga Estação Júlio Prestes \\
\hline 8 & $36990 / 97$ & Res. 27 de 8/7/99 & T & Complexo do antigo Gasômetro \\
\hline 9 & $46662 / 03$ & DOE 13/09/06 & T & Antigo conj. Moinhos Minetti Gamba \\
\hline 10 & $55902 / 07$ & DOE 29/04/09 &
\end{tabular}

TABELA 03: Patrimônio industrial tombado na cidade de São Paulo pelo CONDEPHAAT (T: Tombado). Fonte: Elaborada pelo autor a partir de dados do CONDEPHAAT (Listagem dos bens tombados), acesso em 20 Nov. 2011 e Secretaria Municipal da Cultura (Resoluções do CONDEPHAAT), acesso em 26 jan 2012, disponíveis respectivamente em: $<$ http://www.cultura.sp.gov.br/portal/site/SEC/menuitem.fe8f17d002247c2c53bbcfeae2308ca0/?v gnextoid=300d6ed1306b0210VgnVCM1000002e03c80aRCRD>

<http://www. prefeitura.sp.gov.br/cidade/secretarias/cultura/cit/index.php?p=1157>

\section{Municipal}

\subsection{SEMPLA e DPH:}

No âmbito municipal considera-se relevante para este estudo abordar a questão patrimonial e sua conexão com instâncias relacionadas ao planejamento urbano, uma vez que ocorreram antes da criação do Conselho Municipal de Preservação do Patrimônio Histórico, Cultural e Ambiental da Cidade de São Paulo (CONPRESP) instituído em 27 de dezembro de 1985 (Lei $n^{\circ}$ 10032), cujos tombamentos somente se efetivaram a partir de 1988.

Como mencionado anteriormente, na década de 1970 mediante o desenvolvimento do conceito de bem cultural os profissionais do patrimônio passaram a admitir o valor cultural dos bens no contexto urbano. Dessa forma, a Coordenadoria Geral de Planejamento (COGEP) - atual Secretaria Municipal de Planejamento (SEMPLA) da Prefeitura Municipal de São Paulo (PMSP) iniciou em 1974 o cadastramento das edificações e logradouros paulistanos a serem protegidos. Esse trabalho foi inspirado na experiência francesa de demarcar "setores preservados" objetivando 
orientar a nova legislação de zoneamento urbano (RODRIGUES, 2000, p. 71-72). Foram criadas manchas, classificadas como Z8-200 definidas como "imóveis de caráter histórico ou de excepcional valor artístico, cultural ou paisagístico, destinados à preservação." (FENERICH, 2000, p. 8). A delimitação espacial que embasava as Z8-200 foi o critério de seleção dessa listagem que foi a primeira forma de preservação de bens culturais pelas autoridades municipais. A princípio se concentrou na área central, e, posteriormente, outros imóveis foram incorporados através de estudos de renovação urbana como a Zona Metrô-Leste, ou ainda, pela inclusão de imóveis tombados pelo CONDEPHAAT.

Estas zonas estavam sujeitas a medidas específicas estabelecidas na legislação de uso e ocupação do solo do município - Lei 8328/75. Dentre as "manchas" estabelecidas muitas estavam relacionadas a aspectos socioeconômicos, à imigração, à estrada de ferro e à industrialização. Esse mecanismo de enquadramento de novos bens não se constituiu em uma prática sistemática e o último enquadramento se deu em 1989. O estabelecimento das Z8-200 tem um caráter apenas preventivo em que há um interesse maior pelo valor do conjunto do ambiente urbano, distinto do tombamento. Sendo assim, não são todas as Z8-200 que foram posteriormente tombadas pelo CONPRESP (FENERICH, 2000, p. 173).

A Divisão de Preservação foi criada em 1975 como uma segmentação do Departamento do Patrimônio Histórico (DPH) e somente começou atuar em 1977 quando seu quadro técnico foi constituído. Nesse ano, foi realizado um trabalho pela Divisão de Preservação em conjunto com a COGEP solicitados pela Cia. Do Metrô para a identificação de bens culturalmente significativos que seria a área imediata de influência da linha Metrô-Leste então em construção (BAFFI, 2006, p. 169). Esse estudo - Patrimônio Ambiental Zona Metrô-Leste - extrapolou os limites da ZML e selecionou imóveis abrangendo, dentre outros, a arquitetura industrial. Embora esse inventário tenha se tornado uma importante referência para atividades posteriores da Divisão de Preservação, não atingiu o objetivo de preservar os bens selecionados na pesquisa. Em 1978, foi encaminhado um projeto, propondo a inclusão desses bens estudados na relação das Z8-200; porém, esta proposta foi recusada por força das pressões feitas pelos proprietários das edificações industriais (BAFFI, 2006, p. 173). Ainda assim, alguns imóveis como o Gasômetro (Z8-200-102) - desativado em 1972 
- constituído da Casa das Retortas, do muro frontal e da chaminé externa foram englobados às Z8-200 pela Lei No 8848.78 (FENERICH, 2000, p. 172).

Houve também o trabalho encomendado pela Cia. Do Metrô para o tramo oeste que analisou 91 quadras ao longo da linha férrea na região dos bairros da Lapa, Água Branca e Barra Funda ressaltando o desenvolvimento relacionado à primeira fase da industrialização da cidade. Logo na introdução está explícito que há um interesse em "[...] identificar, para fins de preservação, os bens culturais na região oeste da cidade de São Paulo, situados ao longo das linhas que constituem as diferentes alternativas para o traçado do tramo oeste do metrô" (SÃO PAULO, 197?a, p. 4). Esse trabalho não resultou, porém, em nenhuma ação efetiva para a preservação dos imóveis estudados, dentre eles exemplares do patrimônio industrial.

Ainda nesse período houve também o levantamento parcial Galpões Industriais Significativos realizado pela Empresa Municipal de Urbanização (EMURB) que teve como objetivo estudar o uso do solo enfocando dados caracterizadores dos Bairros do Brás e Mooca como os galpões industriais e as vilas habitacionais mais significativos. Essa proposta tinha como meta oferecer condições a entidades públicas ou privadas para a preservação da memória urbana; encontrar caminhos através de instrumentos legislativos para uma reintegração (reciclagem) dos espaços às novas condições de uso da cidade, subsidiando planos de reurbanização daquela área quando terminassem as obras do metrô. Os edifícios levantados geralmente são da primeira fase de industrialização da cidade e são subdivididos em três categorias: I Galpões Significativos; || Conjuntos Industriais Significativos e III Áreas Industriais Significativas. Foram considerados "significativos" segundo os seguintes critérios: o conjunto, por suas características arquitetônicas; época da construção; área do lote; característica de uso e relação com a malha urbana (SÃO PAULO, 197?b).

Analisando os imóveis listados nas Z8-200 (Tabela 04) há poucos que estão relacionados diretamente ao patrimônio industrial, a maioria está inclusa na lei de 1975 na análise da área central como a Vila Economizadora, a Estação da Luz e a Estação Júlio Prestes. Em 1978 foram indexados o Gasômetro, como já mencionado, e a Estação do Brás; em 1984 o Antigo Matadouro da Vila Mariana. 


\begin{tabular}{cccc}
\hline & Data & Número & Nome \\
\hline 1 & Lei 1975 & Z8-200-020 Mancha 4 & Vila Economizadora \\
\hline 2 & Lei 1975 & Z8-200-021 Mancha 6 & Estação da Luz \\
\hline 3 & Lei 1975 & Z8-200-021 Mancha 6 & Estação Júlio Prestes \\
\hline 4 & Lei 1978 & Z8-200-102 & Gasômetro \\
\hline 5 & Lei 1978 & Z8-200-104 & Estação do Brás \\
\hline & & & Z8-200-129
\end{tabular}

TABELA 04: Patrimônio industrial relacionado nas Z8-200. Fonte: Elaborada pelo autor a partir de dados levantados junto à pesquisa FENERICH (2000).

\subsection{CONPRESP:}

Com a criação do CONPRESP em 1985 e sua efetiva atuação a partir de 1988, todos os imóveis tombados nas esferas Federal e Estadual no município foram incorporados ex-officio. Logo no início da década de 1990, verifica-se a incidência de alguns remanescentes relacionados ao patrimônio industrial por parte do órgão municipal.

Uma dessas primeiras resoluções dispõe sobre a Vila Operária Triângulo e a Companhia Nacional de Cimento Portland Perus (1926). Desde 1987, as casas da vila operária estavam ameaçadas de demolição pela empresa. Em 1989, após estudos e vistorias do DPH, foi aberto o processo de tombamento que englobava a ferrovia, sua área envoltória e a vila. $O$ processo de tombamento foi contestado pela Companhia Perus de Desenvolvimento Urbano, Ferrovia Perus Pirapora Ltda. e a Companhia Nacional de Cimento Portland Perus, alegando que a Vila Triângulo não tinha nenhum valor que justificasse o processo (FENERICH, 2000, p. 137-139 e RODRIGUES, 2001, p. 97). O aprofundamento das pesquisas confirmaram o valor histórico, social e urbanístico do conjunto justificando o tombamento definitivo através da Resolução 27/92.

$\mathrm{Na}$ sequência, foi solicitado o tombamento de dois representativos conjuntos industriais: o Moinho Matarazzo e a Tecelagem Mariângela. A Resolução 38/92 confirma os valores que justificam o tombamento desses imóveis: a importância da 
memória dos trabalhadores; o valor urbanístico representado pela ocupação industrial ao longo das ferrovias na primeira fase de industrialização da cidade e o valor histórico-arquitetônico, ambiental e afetivo. $\mathrm{Na}$ ocasião o antigo Moinho Matarazzo fazia parte do então Grupo Comolatti e era usado para a estocagem de fardos de algodão. A antiga tecelagem Mariângela estava sendo usada para um "Shopping da Construção", seus proprietários contestaram a resolução do tombamento alegando que o prédio havia perdido seu caráter histórico com a instalação do centro comercial (7). Mesmo assim, a importância da edificação foi reiterada pelo corpo técnico do CONPRESP e o tombamento efetivado.

Na sequência foi tombada a Vila Maria Zélia e parte da antiga fábrica, conjuntos que haviam sido estudados em 1978 no processo da Zona Metrô Leste, havendo, inclusive, um pedido do DPH de enquadramento da Vila como Z8/200. A Vila Maria Zélia foi tombada praticamente ao mesmo tempo (dezembro de 1992) tanto pelos órgãos municipal e estadual. Em sua justificativa para 0 tombamento, 0 CONDEPHAAT destacou o pioneirismo, a originalidade e a representatividade de suas características de implantação e uso enquanto empreendimento do início do século (FENERICH, 2000, p. 120-121). Ao tombá-la em 1992, o CONPRESP também ressaltou os valores urbanístico, histórico, arquitetônico, ambiental e afetivo das edificações, destacando ser esse o "mais bem acabado exemplo de 'vila cidadela' existente na cidade de São Paulo." (ROLNIK apud SÃO PAULO, SMC/CONPRESP, Res. 39/92, p. 91). No que diz respeito ao conjunto da fábrica, o processo do CONPRESP reconheceu oficialmente 3 edificações diferindo do tombamento estadual, que não a incluiu.

Conforme análise da pesquisadora Cíntia Nigro Rodrigues referindo-se ao volume de edificações tombadas nesse período pelo CONPRESP, esse primeiro impulso da década de 1990 pode estar vinculado a uma abertura deste órgão à participação da sociedade civil. A intensificação da procura pelas diversas entidades civis solicitando o tombamento de bens de interesse cultural gerou um maior "dinamismo" na efetiva operacionalização do CONPRESP (RODRIGUES, 2001, p. 93).

Após esse período, verifica-se certa estagnação no decorrer dos anos posteriores em relação aos tombamentos do patrimônio industrial que pode ser constatado ao 
verificar a listagem oficial do CONPRESP. Como resultado direto, diversos imóveis representativos da memória industrial vem acumulando descaracterizações, foram abandonados indiscriminadamente, ou ainda foram demolidos e suas respectivas áreas vendidas devido ao grande valor imobiliário adquirido mediante ao crescimento e às mudanças na configuração econômica da cidade que derivam de uma significativa alteração no uso do solo das antigas áreas estritamente industriais. Analisando a listagem dos bens tombados ou em estudo pelo CONPRESP (Tabela 05), é possível constatar que houve um substancial crescimento dos bens relacionados ao patrimônio industrial principalmente a partir de 2004.

\begin{tabular}{|c|c|c|c|}
\hline & IMÓVEIS TOMBADOS: & ENDEREÇO & $\mathbf{T}$ \\
\hline 1 & Antiga Estação do Brás da São Paulo Railway & Praça Agente Cícero, s/ No & $05 / 91$ \\
\hline 2 & Edifícios do Antigo Matadouro de Vila Mariana & Lg. Sem. Raul Cardoso, 133, 207 e Rua Sena Madureira, 112, 124 & $05 / 91$ \\
\hline 3 & Indústrias Reunidas Francisco Matarazzo & Av. Francisco Matarazzo, 1096 - & $05 / 91$ \\
\hline 4 & Estação da Luz & Pç da Luz & $05 / 91$ \\
\hline 5 & Vila Economizadora & R. São Caetano / Av. do Estado/ Linha Férrea/ R. da Cantareira & $05 / 91$ \\
\hline 6 & Antiga Companhia Brasileira de Cimento Portland Perus & Vila Triângulo & $27 / 92$ \\
\hline 7 & Moinho Matarazzo & R. Monsenhor Andrade, 640 x Rua Flórida, 77 & $38 / 92$ \\
\hline 8 & Tecelagem Mariângela & R. Monsenhor Andrade, 367 x Rua Fernandes Silva, 296 & $38 / 92$ \\
\hline 9 & Antiga Fábrica Maria Zélia e Vila Maria Zélia & Rua dos Prazeres, 106/284 e Av. Celso Garcia, 1613/ 1627/1645 & $39 / 92$ \\
\hline 10 & Farol e Relógio do Jaguaré (ZEPEC) & R. Salatiel Campos & $02 / 02$ \\
\hline 11 & Galpões da antiga fábrica UNILABOR & R. Vergueiro, 7.290 - Capela do Cristo Operário & $11 / 04$ \\
\hline 12 & Tendal da Lapa & R. Guaicurus, 1016 e Rua Constança, 68, 72, 102 & $10 / 07$ \\
\hline 13 & Antigas Officinas da Sociedade Anônima Casa Vanorden & R. Monsenhor Felipo, 01 & $14 / 07$ \\
\hline 14 & Antigo Conjunto de depósitos para café (CEAGESP) & R. Borges de Figueiredo, 1098 a 1250 & $14 / 07$ \\
\hline 15 & Antigo Conjunto Grandes Moinhos Minetti Gamba & R. Borges de Figueiredo, 510 e 448 & $14 / 07$ \\
\hline 16 & Antigo Conjunto Sociedade Técnica Bremensis e Schmidt Trost & R. Borges de Figueiredo, 1294 e 1358 & $14 / 07$ \\
\hline 17 & Conjunto de Armazéns da Antiga São Paulo Railway & Av. Presidente Wilson, 1009 & $14 / 07$ \\
\hline 18 & Galpão Industrial & R. Borges de Figueiredo, 964 a 1004 e 1030 a 1084 & $14 / 07$ \\
\hline 19 & Antiga Cooperativa de Cotia & Av. Kenkiti Shimomoto entre as Av. Jaguaré e José Maria da Silva & $05 / 09$ \\
\hline 20 & Fábrica da Vidraria Santa Marina & Av. Santa Marina entre a Av. Ermano Marchetti e leito da CPTM & $05 / 09$ \\
\hline 21 & Galpão Fabril da Antiga Metalúrgica Martins Ferreira & R. Wiliam Speers, 1180 a 1222 & $05 / 09$ \\
\hline 22 & Antiga Fábrica de Tubos de Barro & Av. Santa Marina, 372, 394 & $05 / 09$ \\
\hline 23 & Comp. Melhoramentos de São Paulo (administração) & R. Tito, 479 x R. Espártaco, 685 & $05 / 09$ \\
\hline 24 & Galpão Industrial & R. Padre Chico, $780 \times$ R. Raul Pompéia & $05 / 09$ \\
\hline 25 & SESC Pompéia & R. Clélia, 93 x Rua Br. Do Bananal, s/n & $05 / 09$ \\
\hline 26 & Estação Ciência & Rua Guaicurus, 1270 a 1475 & $05 / 09$ \\
\hline 27 & Antiga Companhia de Refinadores União - chaminé & R. Borges de Figueiredo x R.João Antonio de Oliveira & $05 / 10$ \\
\hline 28 & Fábrica de Fósforos Fiat Lux & R. Borges de Figueiredo, 680 a 828 & $30 / 01 / 12$ \\
\hline 29 & Fábrica da Duchen & R. Borges de Figueiredo, 680 a 828 & $30 / 01 / 12$ \\
\hline 30 & IRFM - ramal ferroviário e chaminé & R. Borges de Figueiredo, 680 a 828 & $30 / 01 / 12$ \\
\hline & ABERTURA DE PROCESSO DE TOMBAMENTO: & ENDEREÇO & APT \\
\hline 1 & Oficina metalúrgica artesanal & R. Santo Amaro & $03 / 90$ \\
\hline 2 & Balões da Comgás (ZEPEC) & R. da Figueira, 479 x Rua Capitão Faustino Lima, 34 & $19 / 91$ \\
\hline 3 & Antiga Fábrica Bom Pastor & R. Bom Pastor, 2.072/2.104/2.112/2.140 & $05 / 92$ \\
\hline 4 & Antiga Garagem de Bondes da Light & Av. Celso Garcia, 142 e 157 e R. Dr. Costa Valente, 314 e 358 & $34 / 92$ \\
\hline 5 & Estação Júlio Prestes & Pç. Júlio Prestes, 148 e 268 x R. Mauá, s/n & $44 / 92$ \\
\hline 6 & Casa das Retortas & Rua do Gasômetro, 100 & $44 / 92$ \\
\hline 7 & Companhia Antarctica Paulista & Av. Presidente Wilson, 251, 307 e 367 & $09 / 07$ \\
\hline 8 & Cavas de ouro ( 4 conjuntos) & Região do Jaraguá & $06 / 11$ \\
\hline 9 & Companhia Nitro Química Brasileira & Av. Dr. José Artur Nova, 951 & $10 / 11$ \\
\hline
\end{tabular}

TABELA 05: Patrimônio industrial tombado $(\mathrm{T}$ ) e com abertura de processo de tombamento (APT) na cidade de São Paulo pelo CONPRESP. Fonte: Elaborada pelo autor a partir de dados do CONPRESP (Índice geral), acesso em 2 fev. 2012, disponível em: 
<http://www. prefeitura.sp.gov.br/cidade/secretarias/cultura/conpresp/indice_geral/index.php?p=1 $142>$.

Considerando que a cidade de São Paulo conta com um profícuo campo de estudos para o patrimônio industrial, já que o desenvolvimento de sua estrutura urbana está vinculada à indústria, o aumento nos bens tombados ou em estudo pelo CONPRESP pode estar vinculado a uma ampliação de conscientização a respeito da importância do valor cultural e documental desses bens. O aumento do número de publicações, seminários e trabalhos acadêmicos com diversas abordagens (questões técnicas, histórico - sociais, econômicas, arquitetônicas, urbanas, culturais, etc.) reflete não só a potencialidade do tema como a eminente necessidade de discuti-lo e desenvolvê-lo (8).

Nesse sentido, podem ser mencionadas algumas iniciativas determinantes para compreender o processo de valorização do patrimônio industrial analisado aqui cuja abrangência não se limita à cidade de São Paulo. Em 1998 foi formulada a Carta de Campinas, que consiste numa declaração oficial do GEHT (Grupo de Estudos da História e da Técnica - UNICAMP) firmada por signatários de 24 cidades de 4 países (Brasil, Colômbia, Estados Unidos da América e Portugal) em que foram determinadas normas e princípios em relação à preservação desses artefatos. Em 2003 foi fundado o Comitê Brasileiro de Preservação do Patrimônio Industrial, seção nacional da organização internacional $\mathrm{TICCIH}$, formado por diversos profissionais das áreas de sociologia, história, arquitetura, dentre outras. Em 2004 foi realizado o I Encontro Nacional sobre Patrimônio Industrial em Campinas e em 2009 foi promovido o II Encontro Nacional em São Paulo.

Outro aspecto da ampliação na percepção em relação ao valor do patrimônio industrial está refletido naquilo que deriva do atual Plano Diretor Estratégico do Município de São Paulo (Lei 13430/2002) e, especificamente, da Lei de Uso e Ocupação do Solo (Lei 13872/2004) em que a população foi consultada e foram selecionadas áreas de importância cultural para serem estudadas para eventual tombamento, as denominadas Zona Especial de Proteção Cultural (ZEPEC). Ao verificar as tabelas das ZEPEC, é possível identificar complexos industriais (Tabela 06), principalmente nos subdistritos em que o desenvolvimento urbano está 


\section{estreitamente relacionado com o primeiro processo de industrialização da cidade como Lapa e Mooca.}

\begin{tabular}{cllc}
\hline & \multicolumn{1}{c}{ ZEPEC } & \multicolumn{1}{c}{ ENDEREÇO } & APT \\
\hline 1 & Antiga Serraria Americana & Rua Tagipuru / Germaine Buchard/ Av. Francisco Matarazzo & $26 / 04$ \\
\hline 2 & Galpão Industrial & Rua Félix Guilhem, 900,926,932 x R. Engenheiro Fox, 453 & $26 / 04$ \\
\hline 3 & Antigo Edifício Industrial & R. da Mooca, 815 e 775 & $26 / 04$ \\
\hline 4 & Antigo Cotonifício Crespi & R. Taquari, 173 x R. dos Trilhos & $26 / 04$ \\
\hline 5 & Edifício Industrial & Av. Alcântara Machado com R. Dr. Almeida Lima (atual fábrica 5) & $26 / 04$ \\
\hline 6 & Edifício Industrial & R. Thiers xR. Hanemann, 335 & $26 / 04$ \\
\hline 7 & Edifício Industrial antigo Colégio São Judas & R. Javari, 403 & $26 / 04$ \\
\hline 8 & Antigo Lanifício Paulista & R. Bohemer, 66 e 106 & $26 / 04$ \\
\hline 9 & Edifício & R. Joly, 179 e 273 XR. Manuel Vitorino, 322,280 e 232 & $26 / 04$ \\
\hline 10 & Edifício & R. Joly, 143 e 273 XR. Manuel Vitorino XR. Sampson, 146 e 142 & $26 / 04$ \\
\hline 11 & Edifício & R. Joly, 294 XEuclides da Cunha e R. Sampson & $26 / 04$ \\
\hline 12 & Indústria Telemecanique S/A & Av. das Nações Unidas x R. Jaime de Oliveira e Souza & $26 / 04$ \\
\hline 13 & Indústrias Amortex & R. Arnaldo Magniccaro, 521 xR. Agostinho Togneri & $26 / 04$ \\
\hline 14 & Edifício Industrial - Fábrica Orion & R. Behring x R. Fernão de Magalhães xR. Joaquim Carlos, 71 & $26 / 04$ \\
\hline 15 & Antiga Usina de Abastecimento de Energia & Sítio Estrela Dalva: casas/barragem e caixa d'água & $26 / 04$ \\
\hline 16 & Antiga Estação Ferroviária no Jardim Satélite & Rua Plínio Schmidt próximo ao No 547 & $26 / 04$ \\
\hline 17 & Estação do Pari & & $26 / 04$ \\
\hline 18 & Farol e Relógio do Jaguaré & Rua Salatiel Campos & $26 / 04$ \\
\hline
\end{tabular}

TABELA 06: Patrimônio industrial relacionado como ZEPEC na cidade de São Paulo. Fonte: Elaborada pelo autor a partir de dados do CONPRESP (Índice geral), acesso em 10 nov. de 2011, disponível em:

$<$ <ttp://www. prefeitura.sp.gov.br/cidade/secretarias/cultura/conpresp/indice_geral/index.php?p=1 $142>$ 
A partir da determinação das ZEPEC, podem ser entendidas as últimas resoluções de tombamento de patrimônio industrial na cidade de São Paulo (Tabela 05). A resolução 14/07, que trata de algumas significativas edificações em um trecho da Rua Borges de Figueiredo - Mooca, é o resultado de um trabalho minucioso que envolveu um levantamento não só para averiguar o valor histórico arquitetônico das edificações em questão, mas também e, principalmente, as relações com o entorno abordando o conceito de "ambiência urbana" dessa área cuja ocupação está diretamente relacionada ao primeiro período de industrialização da cidade (SÃO PAULO, 2007a, p. 6). Sendo assim, o estudo da paisagem predominantemente horizontal da região foi utilizado de modo a justificar $20 \mathrm{~m}$ como altura máxima das construções envoltórias (SÃO PAULO, 2007b, p. 103), o que gerou grandes contestações do mercado imobiliário que encontra nessas áreas importantes braços para o adensamento residencial na Mooca.

Outras das recentes resoluções também abrangem remanescentes nesse importante endereço industrial da capital paulista. Em 2010 foi tombada a chaminé da antiga Companhia de Refinadores União; o processo se iniciou em 2008 após o início da demolição indiscriminada do conjunto. O último tombamento homologado no início de 2012, que estava aberto desde 2007, abrange as edificações do antigo conjunto das Indústrias Reunidas Francisco Matarazzo; porém esse complexo que abrigou a fábrica de Fósforos Fiat Lux, a Fábrica da Duchen e um ramal ferroviário tem passado por um intenso processo de degradação provocado pelo abandono e pela demolição parcial. Para essa área também existe um projeto, por parte dos incorporadores, tramitando para a aprovação em que estão previstas duas torres de $25 \mathrm{~m}$. Mais uma vez, é contundente o enfrentamento entre os interesses dos proprietários, mercado imobiliário e preservação patrimonial. 
Já a resolução 05/09 abrangeu o subdistrito da Lapa, em que foram tombados 8 das 17 áreas relacionadas a patrimônio industrial, dentre as quais o SESC Pompeia, a Estação Ciência, alguns edifícios da Vidraria Santa Marina e o edifício administrativo da Companhia Melhoramentos de São Paulo (9).

\section{Considerações finais:}

O estudo aqui apresentado aponta uma lenta e gradual incorporação de remanescentes industriais nas políticas de preservação patrimonial oficiais na cidade de São Paulo. Mesmo com a análise segmentada, abordando isoladamente as diferentes esferas (nacional, estadual e municipal), foram verificadas certas semelhanças derivadas de uma base comum de conceitos e critérios que nortearam as ações. Ainda que houvesse a percepção da significativa importância dos artefatos industriais para a memória da cidade, evidenciado pelos estudos que ocorreram na década de 1970, não foram tomadas medidas suficientes para sua proteção. $O 1^{\circ}$ Seminário Nacional de História e Energia, realizado na cidade de São Paulo na década de 1980, estimulou o aprofundamento do tema contribuindo para o aumento dos conjuntos que passaram a ser estudados e tombados, porém ainda de forma tímida diante do grande contingente industrial potencialmente significativo da cidade, consequentemente, há um grande número de descaracterizações, abandonos e demolições que vêm se acumulando ao longo dos anos.

Por outro lado, o aumento significativo, principalmente na última década, de publicações, trabalhos acadêmicos e seminários sobre o tema refletem a evolução da compreensão do valor dos remanescentes industriais, o que está evidenciado pelo aumento concomitante de solicitações de abertura de processos de tombamento (inclusive por segmentos da sociedade civil) e pela homologação oficial dos mesmos nas esferas nacional, estadual e municipal. No entanto, a questão da efetiva preservação ainda passa por percalços na medida em que o ritmo da obsolescência das edificações fabris é iminente, o amplo estado de degradação é uma realidade e o valor imobiliário das áreas industriais é alto.

Como apresentado, tanto na atuação do CONDEPHAAT quanto na do CONPRESP há constantes embates entre o órgão que pretende preservar e os proprietários, gerando contestações, revisões nos processos e até demolições criminosas. 
Atualmente a pressão imobiliária é cada vez mais forte comprometendo a preservação desses bens. Dessa forma, as justificativas de tombamento, como no caso da Mooca (14/07), têm se estruturado de modo mais elaborado a fim de ressaltar incisivamente a importância da preservação desse patrimônio e de considerar sua ambiência urbana.

Tendo em vista essa trajetória de reconhecimento do valor dos remanescentes industriais na cidade de São Paulo por parte das esferas públicas, evidencia-se então a necessidade de seguir os trabalhos de estudo e inventariação que possam subsidiar eventuais tombamentos e que são fundamentais para a efetiva preservação, na medida em que podem promover uma ampliação nas discussões e uma maior conscientização que extrapole os níveis dos órgãos oficiais e acadêmico e englobe a sociedade civil - usuários e proprietários - com o objetivo de minimizar as perdas desse importante legado da memória paulista.

\section{Notas:}

(1) O campo disciplinar da arqueologia industrial se constituiu como o estudo das mudanças sociais, econômicas e culturais a partir da interpretação de evidências materiais compreendendo o levantamento, o registro, a catalogação e a preservação do vasto legado da industrialização. Durante o processo de estruturação dessa disciplina, alguns teóricos se destacaram como os ingleses Kenneth Hudson, R. Angus Buchanan, Arthur Raistrick, Neil Cossons e o francês Maurice Daumas. Em 1978 foi criado o TICCIH (The International Committee for the Conservation of the Industrial Heritage) que em 2003 formulou a Carta de Nizhny Tagil, que apresenta definições, valores e dispõe sobre intervenções no patrimônio industrial sintetizando as asserções teóricas desenvolvidas até então; o texto desse documento menciona como referência a Carta de Veneza (1964).

(2) De acordo com a Carta de Veneza - Artigo 10: "A noção de monumento histórico compreende a criação arquitetônica isolada, bem como o sítio urbano ou rural que dá testemunho de uma civilização particular, de uma evolução significativa ou de um acontecimento histórico. Estende-se não só às grandes criações, mas também às obras modestas, que tenham adquirido, com o tempo, uma significação cultural." (ICOMOS, 1964 In: CURY, 2004, p.92)

(3) O conceito de "patrimônio industrial" aqui utilizado é aquele estabelecido na Carta de Nizhny Tagil (2003), cuja definição demonstra a amplitude potencial que o assunto abarca: "O patrimônio industrial compreende os vestígios da cultura industrial que possuem valor histórico, tecnológico, social, arquitetônico ou científico. Estes vestígios englobam edifícios e maquinaria, oficinas, fábricas, minas e locais de processamento e de refinação, entrepostos e armazéns, centros de produção, transmissão e utilização de energia, meios de transporte e todas as suas estruturas e infra-estruturas, assim como os locais onde se desenvolveram atividades sociais relacionadas com a indústria, tais como habitações, locais de culto ou de educação." (TICCIH, 2003). 
(4) Em 1946, o SPHAN passou a ser designado como Departamento do Patrimônio Histórico e Artístico Nacional (DPHAN); em 1970 o DPHAN é transformado em Instituto do Patrimônio Histórico e Artístico Nacional (IPHAN).

(5) O CNRC estruturou-se em programas de diferentes abrangências, dentre eles o mapeamento do artesanato brasileiro, em que se obtiveram os resultados mais significativos em termos de diversidade e elaboração da problemática. Nos projetos havia a distinção de "fazeres tradicionais" como manifestações culturais distinguindo os codificados (tecelagem) dos que dão margem à criatividade individual (cerâmica). No programa "História da Ciência e da Tecnologia no Brasil", foi idealizado na linha dos ecomuseus o projeto "Museu ao Ar livre em Orleans", Santa Catarina (zona de imigração italiana). Nesse Museu, além da exposição de peças, havia também uma compilação de documentos (fotos, textos, desenhos, relatos de artesãos) de modo a preservar não só os artefatos, mas também a memória do processo de fabricação. Outro projeto interessante foi o "Estudo Multidisciplinar do Caju" que resultou no tombamento pelo IPHAN da Fábrica de Vinho de Caju Tito Silva em João Pessoa (FONSECA, 1997, p. 166 e 169).

(6) Conforme Fenerich, é interessante lembrar que os mesmos proprietários haviam contestado o tombamento da Mansão Matarazzo na Av. Paulista alegando que o conjunto industrial da Água Branca era muito mais expressivo sobre o papel da família Matarazzo no processo de industrialização da cidade. A mansão também foi demolida assim como grande parte do conjunto industrial (FENERICH, 2000, p.120).

(7) Informações obtidas junto a: SÃO PAULO (cidade). SMC/ CONPRESP. Res. 38/92 - Moinho Matarazzo e Tecelagem Mariângela. Processos 1990.0.003.700*0 e 1994-0.011.488-5.

(8) Importantes universidades do Estado de São Paulo têm desenvolvido trabalhos referenciais nessa área, que, inclusive embasaram estudos de tombamento. Dentre eles podem ser mencionados os do grupo de pesquisa da UNICAMP da Faculdade de Filosofia e Ciências Humanas liderado pelas professoras Dra. Cristina Meneguello e Dra. Silvana Barbosa Rubino determinantes para a constituição do TICCIH Brasil. Na USP, as importantes pesquisas do IAU (Instituto de Arquitetura e Urbanismo de São Carlos), bem como do grupo da Faculdade de Arquitetura e Urbanismo liderado pela professora Dra. Beatriz Mugayar Kühl. Na Faculdade de Arquitetura e Urbanismo da Universidade Mackenzie o grupo de pesquisa é liderado pelo professor Dr. Marcos José Carrilho. Essas são apenas algumas referências, mencionadas por terem sido fundamentais para o desenvolvimento deste trabalho. Obviamente existem outros grupos de pesquisa de imenso valor acadêmico em desenvolvimento no âmbito das universidades não só do Estado de São Paulo como de todo o Brasil.

(9) Para uma análise mais detalhada sobre os tombamentos dos edifícios da Antiga Vidraria Santa Marina e da Companhia Melhoramentos de São Paulo, ver capítulos 6,7 e 8 da dissertação de mestrado deste autor: RODRIGUES, Angela Rosch. Estudo do patrimônio industrial com uso fabril da cidade de São Paulo. Dissertação (Mestrado) - Faculdade de Arquitetura e Urbanismo, Universidade de São Paulo, São Paulo, 2011.

\section{Referências bibliográficas:}

ANDRADE, Antônio Luiz Dias. Um Estado completo que pode jamais ter existido. Tese (Doutorado)-Faculdade de Arquitetura e Urbanismo, Universidade de São Paulo, São Paulo, 1993. 
BAFFI, Mirthes I.S. O IGEPAC-SP e outros inventários da Divisão de Preservação do DPH: um balanço. Revista do Arquivo Municipal, São Paulo, v. 204, p. 169-191, 2006.

CURY, Isabelle (Org.). Cartas Patrimoniais. Rio de Janeiro: IPHAN, 2004.

CUNHA, Claudia dos Reis e. O patrimônio cultural da cidade de Sorocaba: análise de uma trajetória. Dissertação (Mestrado)-Faculdade de Arquitetura e Urbanismo, Universidade de São Paulo, São Paulo, 2005.

DEAN, Warren. A fábrica São Luiz de Itu: um estudo de arqueologia industrial. Anais de História, Assis, v. 8, 1976, Assis, SP: Departamento de História, Faculdade de Filosofia, Ciência e Letras de Assis. p. 9-25..

A industrialização de São Paulo (1880-1945). São Paulo: Difusão Européia do Livro, 1971.

FENERICH, Antônia Regina Luz. Preservação em São Paulo: análise de procedimentos metodológicos. Dissertação (Mestrado)-Faculdade de Arquitetura e Urbanismo, Universidade de São Paulo, São Paulo, 2000.

FONSECA, Maria Cecília Londres. O patrimônio em processo: trajetória da política federal de preservação no Brasil. Rio de Janeiro: UFRJ/Minc/IPHAN, 1997.

GAMA, Ruy. Arqueologia industrial e história da técnica. In: SEMINÁRIO NACIONAL DE HISTÓRIA E ENERGIA, 1., 1986, São Paulo. Anais...São Paulo: Eletropaulo, 1986. p. 252-259.

Engenho e tecnologia. São Paulo: Livraria Duas Cidades, 1983.

. A tecnologia e o trabalho na história. São Paulo: Nobel:EDUSP, c1986.

GEHT, Carta de Campinas - Declaração do GEHT em defesa das construções e instalações utilitárias, 1998. Disponível em: <http://cordiolli.files.wordpress.com/2011/06/declara-geht-carta-de-campinas.pdf >. Acesso em: 17 abr. 2012

KATINSKY, Júlio Roberto. Guia para a história da técnica no Brasil colônia. São Paulo: Faculdade de Arquitetura e Urbanismo, Universidade de São Paulo, 1976.

KÜHL, Beatriz Mugayar. Preservação do patrimônio arquitetônico da industrialização: problemas teóricos de restauro. Cotia, SP: Ateliê Editorial, 2009.

LEMOS, Carlos A. C. O que é patrimônio histórico. São Paulo: Brasiliense, 2006.

MENEGUELLO, Cristina. The industrial heritage in Brazil and prospects for the Brazilian Committee for the Conservation of Industrial Heritage. In: INTERNATIONAL TICCIH CONGRESS, 13., 2006, Roma. Industrial heritage and urban transformation - productive territories and industrial landscapes: [proceedings]. Terni, Roma, 2006. (CD - ROM).

MENESES, Ulpiano Toledo Bezerra de. Patrimônio industrial e política cultural. In: SEMINÁRIO NACIONAL DE HISTÓRIA E ENERGIA, 1., 1986, São Paulo. Anais...São Paulo: Eletropaulo, 1986. p. 68-73. 
RODRIGUES, Angela Rosch. Estudo do patrimônio industrial com uso fabril da cidade de São Paulo. Dissertação (Mestrado)-Faculdade de Arquitetura e Urbanismo, Universidade de São Paulo, São Paulo, 2011.

RODRIGUES, Cíntia Nigro. Territórios do patrimônio: tombamentos e participação social na cidade de São Paulo. Dissertação (Mestrado)-Faculdade de Filosofia, Letras e Ciências Humanas, Universidade de São Paulo, São Paulo, 2001.

RODRIGUES, Marly. Imagens do passado: a instituição do patrimônio em São Paulo:1969-1987. São Paulo: Ed. Unesp; Imprensa Oficial; CONDEPHAAT; FAPESP, 2000.

SÃO PAULO (cidade). Companhia do Metropolitano de São Paulo - Metrô - Estudo de Alternativas de traçado Tramo Oeste - Identificação dos Bens Culturais Envolvidos - Vol. I - Diagnóstico. São Paulo: SMC/DPH, 197 ?.

Galpões industriais significativos. São Paulo: EMURB, $197 ?$.

Patrimônio ambiental Zona Metrô Leste. São Paulo: SMC/DPH, 1978.

. IGEPAC - Inventário Geral do Patrimônio Ambiental, Cultural e Urbano de São Paulo. São

Paulo: SMC / DPH, 1987.

Planos Regionais Estratégicos do Município de São Paulo - Subprefeitura Mooca (PRE MO). São Paulo: SEMPLA, 2004. (Série Documentos).

Planos Regionais Estratégicos do Município de São Paulo - Subprefeitura Lapa (PRES - LA).

São Paulo: SEMPLA, 2004. (Série Documentos).

Estudo para o tombamento do Patrimônio Industrial na orla ferroviária em torno da Estação da Mooca. Autoria: THOMAZ, Dalva; GIANNECCHINI, Ana Clara e ARRUDA, Valdir. São Paulo: SMC / DPH, 2007.

Re - Estudo da Área Envoltória dos galpões industriais em torno da Estação da Mooca. Autoria: THOMAZ, Dalva e GIANNECCHINI, Ana Clara. São Paulo: SMC / DPH, 2007.

Resoluções CONPRESP:

SÃO PAULO (cidade). SMC/ CONPRESP. Res. 38/92 - Moinho Matarazzo e Tecelagem Mariângela. Processos 1990.0.003.700*0 e 1994-0.011.488-5.

SMC/ CONPRESP. Res. 39/92 - Vila e Antiga Fábrica Maria Zélia. Processo: 01- 053.41879*50 e Contestação ao Tombamento da Antiga Fábrica Maria Zélia. Processo: 16-007.602-93*04.

SMC/ CONPRESP. Estudo das Zonas Especiais de Preservação Cultural -ZEPECS. Processo: 2004 - 0.297.171-6.

SMC/ CONPRESP. Res. 14/07 - Conjunto dos Edifícios Industriais da Mooca. 
SMC/ CONPRESP. Res. 05/10 Tombamento Chaminé da União.

Processos CONDEPHAAT:

SÃO PAULO (Estado). CONDEPHAAT. Processo 20213/77 - Vila Economizadora.

CONDEPHAAT. Processo 22625/83 - Matadouro da Vila Mariana.

CONDEPHAAT. Processo 24263/85 - Indústrias Reunidas Francisco Matarazzo

CONDEPHAAT. Processo 24268/85 - Vila Maria Zélia.

TICCIH. Carta Niznhy Tagil, 2003. Disponível em:

<http://www.patrimonioindustrial.org.br/modules.php?name=News\&file=article\&sid=29>.Acesso em: 1 nov. 2010.

\section{Créditos}

* Esse artigo é uma versão adaptada e atualizada de um dos capítulos da dissertação de mestrado desenvolvida pela autora Estudo do patrimônio industrial com uso fabril na cidade de São Paulo (2011), com orientação da profa. Dra. Mônica Junqueira de Camargo e apoio da Fundação de Amparo à Pesquisa do Estado de São Paulo (FAPESP).

** Arquiteta e urbanista, mestre em História e Fundamentos da Arquitetura e Urbanismo pela Faculdade de Arquitetura e Urbanismo da Universidade de São Paulo. angelarr@usp.br 